\title{
THE DEVELOPMENT OF METHODS FOR EXAMINING STABILIZERS IN POLYMERS AND THEIR CONVERSION PRODUCTS
}

\author{
ELISABETH SCHROEDER \\ Technische Hochschule für Chemie 'Carl Schorlemmer', \\ Department of High Polymers, Leuna-Merseburg, GDR
}

\begin{abstract}
In the field of stabilizer analysis today there is a need for the analytical determination of the decomposition or transformation products of the stabilizers in polymer systems including their reaction products with the polymers. For the solution of such a complex analytical task, separation problems are at the centre of modern scientific work. These separation problems are subdivided into two partial processes, namely (a) separation of the low molecular substances from the polymer; (b) separation of the mixture of low molecular substances.

Selective stage extractions and gel permeation chromatography are particularly favourable. The well-known method of the precipitation of the polymer from diluted solutions needs a more thorough scientific consideration of the solvent-precipitant effects on the stability of the reaction products of stabilizers or their fragments with the polymer.

Thin-layer chromatography (TLC) has brought the greatest success, multistage processes here also offer prospective possibilities for the separation of complex systems. Gas chromatography (GC) is less important. Liquid chromatography (LC) with new high-efficiency carrier materials having particle diameters in the micro range will be most important in the future.

Structure examinations of the decomposition products of the stabilizers in principle correspond to the classical organo-analytical concepts after separation processes. The most important of the decomposition products of the stabilizers were those of the tin compounds and those of stabilizers based on urea. All toxic substances were detectable by TLC.

Structure examinations of stable transformation products of the nitrogencontaining antioxidants with u.v. and i.r. spectrometry are demonstrated in relation to the most discussed mechanism of the inhibition reaction. An analytical scheme for oxidized vulcanizates in the presence of secondary and tertiary mono- and diamines is given at the end to demonstrate the necessity of combining largely selective separation processes with all analytical detection and determination processes of high sensitivity for a successful overall analytical process.
\end{abstract}

\section{INTRODUCTION}

On the one hand, progress in the field of stabilizer analytical techniques is closely related to progress in all analytical disciplines-especially in the 


\section{ELISABETH SCHROEDER}

instrumental techniques - and on the other it is a reflection of the growing standard of knowledge in the field of the degradation of polymers and their inhibition. The trend of analytical chemistry is less characterized by the search for new measuring principles, but it indicates a preferred accentuation of the increase in the measuring sensitivity, selectivity, reproducibility and speed, of which the most important at present are the increase in sensitivity and selectivity for the stabilizer techniques. While in the 'fifties research work here was concentrated on the evidence and quantitative determination of stabilizers or their mixtures in polymers, today there is the demand for analytical determination of the decomposition or conversion products of the stabilizers in polymer systems including their reaction products with the polymers. This task, which is for the analyst both difficult and at the moment only conditionally soluble, results from the high demands made by all of us everywhere on the toxic purity of a plastic material used as a commodity, as well as from the necessity of an analytical backing for explaining the mechanism of action of stabilizers when they are used in polymers to prevent their destruction by heat, oxidation, light or by the combined effect of these and other factors. The field of work for stabilizer techniques thus arises not only from scientific but also from economic points of view and confronts scientists who seek to protect human health against noxious environmental influences.

\section{ACCENTS IN STABILIZER ANALYSIS}

\subsection{Separation problems}

\subsubsection{Isolation of stabilizers and their decomposition products}

The solution of so complex an analytical task as stabilizer analysis (see Figure 1) cannot be achieved without highly efficient separation processes for the comprehensive preliminary separation of the mixture of substances

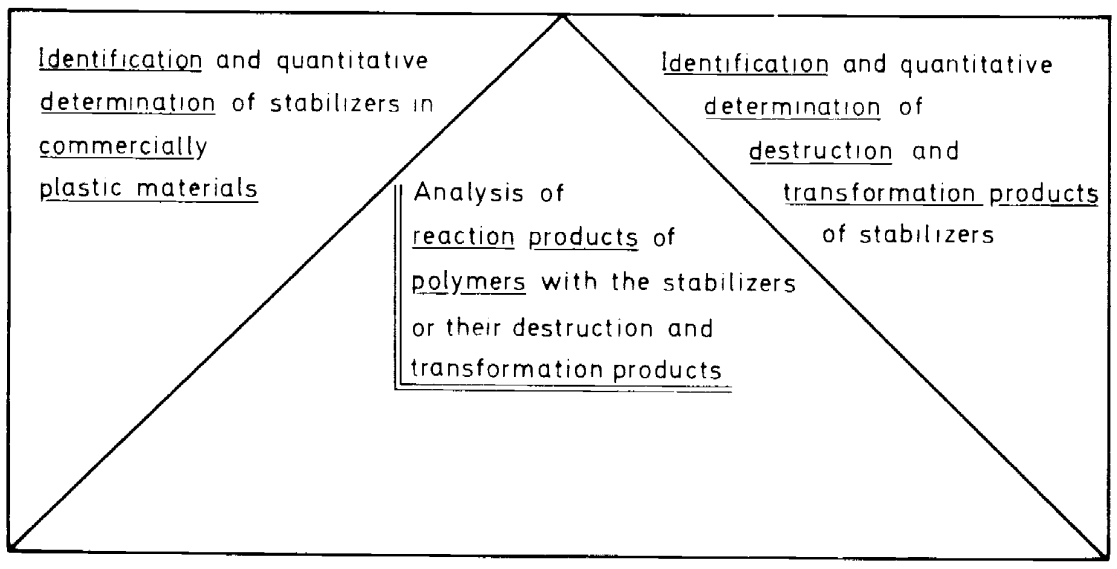

Figure I.Problems of stabilizer analysis 
despite all progress in the analytical chemistry, i.e. in particular by increasing the resolving power of absorption-spectrometric processes, by increasing the sensitivity in emission analysis as well as the selectivity of electrochemical methods, furthermore by chelatometry and also by radiochemical analysis. Therefore, separation problems, apart from structure research, are at the heart of modern scientific work and are to be dealt with also at the beginning of this paper. This, however, should not lead to the conclusion that efforts regarding in situ analysis are of secondary importance only, which is now as hitherto the method chosen for routine analysis of commercial products of comparable pre-treatment. Due to the large differences between molecule sizes of the predominantly low-molecular or oligomer stabilizers and the polymers and the great differences thus arising in the solubility, adsorption or diffusion behaviour, respectively, the separation routines even nowadays are subdivided into two partial processes, i.e. (a) separation of the low molecular substances from the polymer, and (b) separation of the mixture of low molecular substances. Solid/liquid extraction and polymer precipitation are even now the preferred methods amongst the numerous possibilities for the separation of low molecular substances. Taking into account the solvent effects on the extraction behaviour as well as the morphology of the polymers, optimum conditions of work have resulted from the abundance of publications for the appropriate polymer-stabilizer systems. An extract is given in Table 1 (see refs. 1,2).

Table 1. Extracting solvents for stabilizers

\begin{tabular}{lll}
\hline Polymer type & Substances extracted & Extracting solvents \\
\hline PVC & Organo-tin stabilizers & Heptane-acetic acid $1: 1$ \\
PVC & Organic- $N$-compounds stabilizers & Methanol or ether \\
PE & Antioxidants & Chloroform \\
POM & Phen. antioxidants & Chloroform \\
Rubber and & Stabilizers & Boiling acetone \\
vulcanizates & Accelerators & Boiling water \\
\hline
\end{tabular}

Apart from single-stage extraction, selective stage extractions are particularly favourable for the problems set by the analysis of plastics auxiliaries, because they already permit a preliminary separation of complex systems, although it is a rather coarse one. An excellent example for the selective extraction of stabilizers is amongst others that of the analysis of polyformaldehyde types ${ }^{3}$ where the antioxidant used is extracted with chloroform and the heat stabilizer (dicyanodiamide) subsequently with methanol.

Under the new aspect of the stabilizer analytical techniques already described, however, even simple extraction processes present some complications which may result in faulty interpretation. From the function of the stabilizers to be expected, a high reactivity and lability result of necessity, which may lead to rearrangements, decompositions and similarly conditioned losses already with these first analytical operations. Despite the avoidable oxidative changes of the stabilizers, even the crushing phase of the polymer preceding the extraction means a source of danger. As is a well-known fact, all polymers of larger chain-lengths suffer from a degrada- 


\section{ELISABETH SCHROEDER}

tion under mechanical stress which usually starts by a chain rupture in the centre of the macro-molecule and results in the formation of macro radicals. This degradation is accelerated at low temperatures and even occurs when cutting with a knife. By means of quantitative examinations, Pazonyi et al. ${ }^{4}$ were able to find a linear relationship between the radical concentration (determined by the consumption of diphenyl-picryl-hydrazyl) and the surface (Figure 2) when cutting polyethylene and plastiziced PVC. They could prove that the chemical bonds with polymers which to some extent are present in the elastic state are cut by mechanical forces with 100 per cent efficiency. In the presence of inhibitors reactions between macro radical and inhibitor may occur even in the absence of oxygen. As a consequence reaction products with the polymers themselves, but also deactivation products of the intermediately formed inhibitor radical are to be expected.

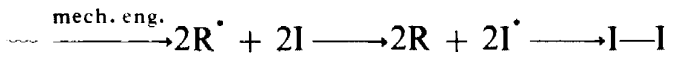

Thus, for instance, Kenyon ${ }^{5}$ also accepts an attachment of butyl residues of dibutyl-tin-diacetate to PVC radicals formed by u.v. radiation according to

$$
\mathrm{R}^{\cdot}+\left(\mathrm{C}_{4} \mathrm{H}_{9}\right)_{2} \mathrm{Sn}\left(\mathrm{CH}_{3} \mathrm{COO}\right)_{2} \rightarrow \mathrm{R}-\mathrm{C}_{4} \mathrm{H}_{9}+\mathrm{C}_{4} \mathrm{H}_{9} \mathrm{Sn}\left(\mathrm{CH}_{3} \mathrm{COO}\right)_{2}
$$

which has been confirmed by examination results obtained by Frye et al. ${ }^{6}$ with ${ }^{14} \mathrm{C}$ butyl-labelled organotin compounds. In the presence of oxygen the reaction probability of the macro radicals with the inhibitor system is increased considerably mainly if phenolic or aminic antioxidants are present. Further information losses on reaction-induced decomposition products mainly occur when the extracts obtained are re-concentrated. Even the inherent volatility of some antioxidants - above all that of the phenols and aromatic amines (Table 2) - is so high that it provides the basis of a direct

Table 2. Volatility of antioxidants (see ref. 24)

\begin{tabular}{lcc}
\hline Antioxidant & $\begin{array}{c}\text { Vapour pressure } \\
{[\mathrm{mm} \mathrm{Hg}]}\end{array}$ & $\begin{array}{c}\text { Loss of weight } \\
\text { (150 () }\end{array}$ \\
\hline 2,6-Di-t-butyl-p-cresol & 22.15 & 100 \\
2-Benzyl-6- $t$-butyl-p-cresol & 1.83 & 100 \\
$2,2^{\prime}$-Methylene-bis-6-t-butyl-p-cresol & 0.169 & $19 \ldots 28$ \\
Diphenylamine & 7.52 & 100 \\
$N$ - $i$-Propyl- $N^{\prime}$-phenyl-p-phenylene- & 0.59 & $40 \ldots 53$ \\
diamine & 0.032 & $2 \ldots 3$ \\
$N$ - $N^{\prime}$-Diphenyl- $p$-phenylenediamine & &
\end{tabular}

determination in the polymer by vacuum sublimation as suggested by Yushkevichyute $^{7}$ for the determination of antioxidants in PE and also can be applied to the explanation of the mechanism of action of phenolic and aminic antioxidants in PE and $\mathrm{PP}^{8}$. Thus a separation by distillation of the 2,6-di-t-butyl-4-methylphenol from its dimer deactivation product at $100^{\circ} \mathrm{C}$ was successful and provided evidence for the isomerization of the primarily formed phenoxy radicals to oxybenzyl radicals and their recombination to dioxydiphenylethane: 


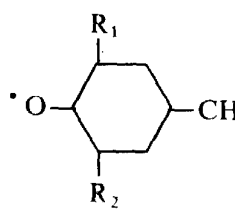<smiles>[R]C1CC(C)CC([R])C1O</smiles><smiles>[R]C1CC(CCC2CC([R])C(O)C([R])C2)CC([R])C1O</smiles>

On the other hand the high volatility with the classical way of re-concentrating the extracts by distillation-even by evaporation of the solutions-of course will result in considerable loss of substance as we found in examinations with the same antioxidant ${ }^{9}$. We even found an evaporation loss of 0.75 per cent after 24 hours when storing Jonol with a large surface in stagnant air. This loss increased to 63 per cent when the chloroform solution was evaporated in a fume cupboard.

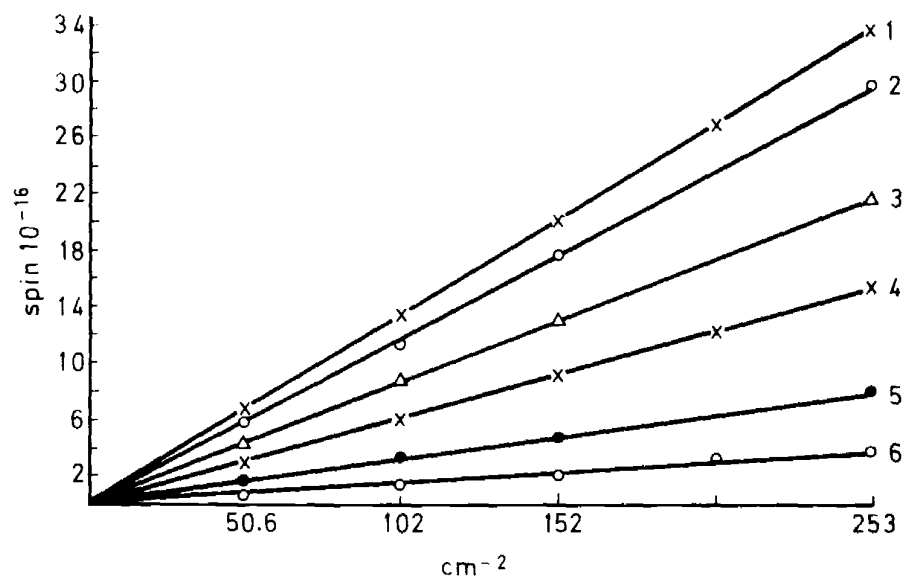

Figure 2. Consumption of radicals in relation to surface area

Distillation processes--even careful freeze-drying-should be avoided tor quantitative work in systems of such high volatility as the stabilizers, especially if also quantity and type of the decomposition products are of interest. In such cases only an enrichment by chromatographic processes should be considered. From the point of view of separation from the polymer, gel-permeation chromatography is a possible method since the separation of molecules in the pores of the gels is mainly achieved according to particle size, and the large polymer molecules can be excluded from the separation process by suitable selection of the pore size distribution of the gels so that they leave the separation column together with the solvent. Such a separation of low molecular substances from polymer mixtures have already been described for plasticizers ${ }^{12}$, oils ${ }^{13}$ and methylsilanoles ${ }^{14}$. It is to be seen 


\section{ELISABETH SCHROEDER}

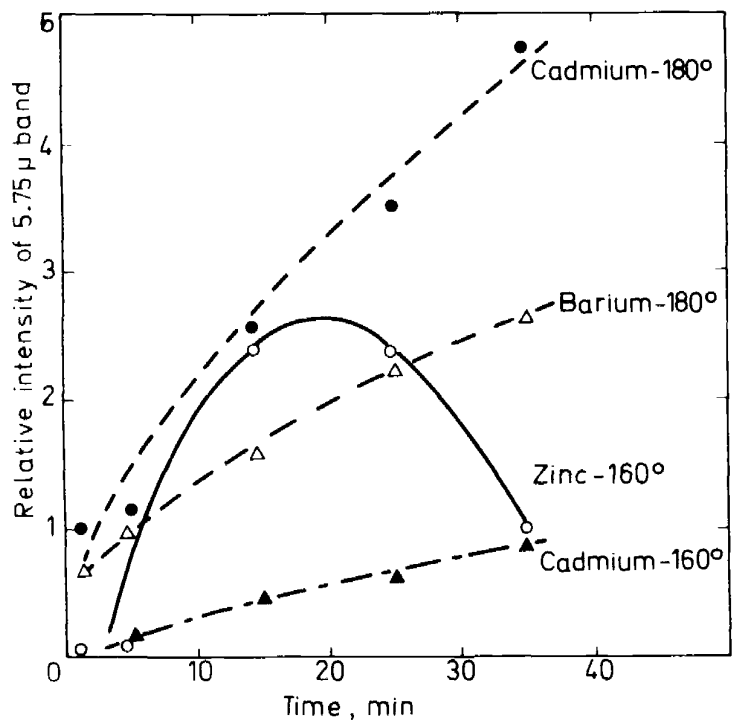

Figure 3. Relative intensities of the $5.75 \mu$ band after various heat treatments in purified poly(vinyl chloride)

from the interesting papers of Coupek and Pospiśili ${ }^{10,11}$, who deal systematically with this problem, as to how far the stabilizer mixture is separated subsequently.

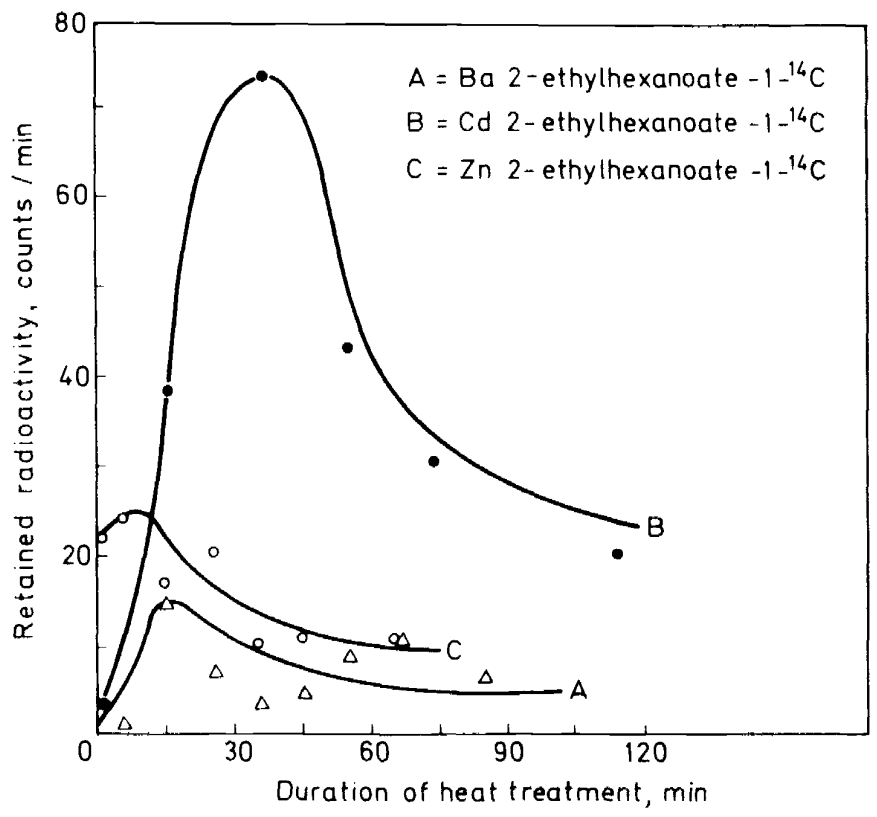

Figure 4 


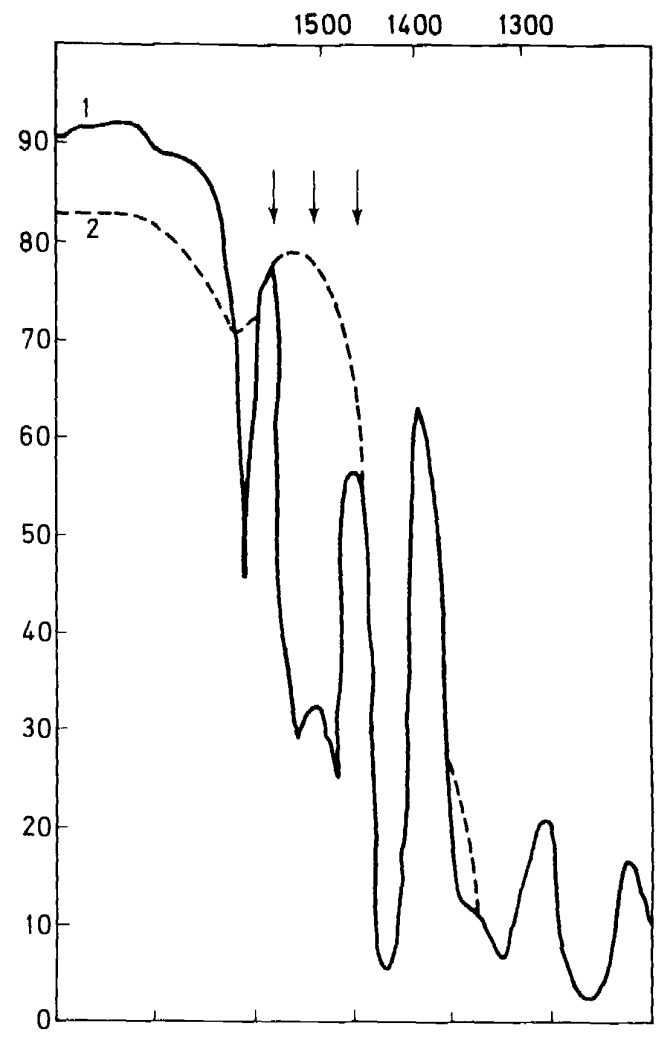

Figure 5. The i.r. spectrum of PVC with diphenylthiourea (1) before, (2) after heating at $165^{\circ} \mathrm{C}$

With the well-known method of precipitation of the polymer from diluted solutions for the separation of soluble low molecular substances, the negative influences of the mechanochemical degradation during the crushing stage and the consequent reaction released are eliminated, but again this process needs a more thorough scientific consideration of the solution-precipitant effects on the stability, especially of the reaction products of stabilizers or their fragments with the polymer, under the new objectives of stabilizer analytical techniques. Such reaction products have been both determined and isolated with PVC, PE, PP and natural rubber.

Thus Frye $e t$ al. were able to provide evidence by i.r. spectroscopy ${ }^{15}$ and radiochemistry ${ }^{16}$ of the insertion of ester groupings from barium, cadmium or zinc-carboxylates in PVC after heat treatment (Figures 3 and 4). Tin contents and organic residues of organotin stabilizers in heat-treated PVC are indicated by the same authors ${ }^{5,17,18}$; Schlimper ${ }^{19}$ and Hagen ${ }^{20}$ proved the direct reaction between PVC and nitrogen-containing organic stabilizers (Figure 5) by elemental analytical examinations and i.r. and u.v. spectrometry. Phenolic antioxidants or their decomposition products in 


\section{ELISABETH SCHROEDER}

part were re-found in PP after oxidative degradation ${ }^{8}$ : with rubber vulcanizates hydrochloric acid-resistant amine-rubber compounds are described after thermal oxidation in the presence of aromatic amines ${ }^{21}$. With

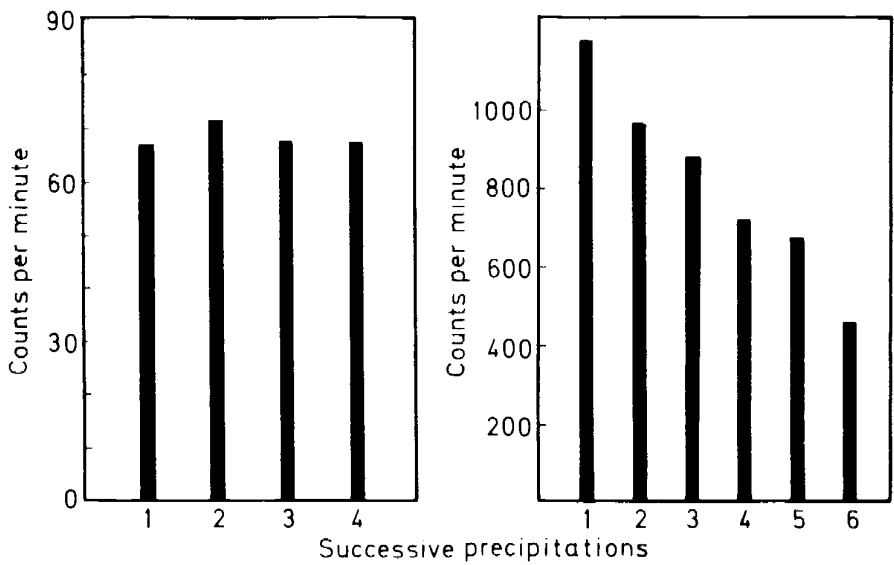

(a) Cd 2-ethylhexanoate $-1-^{14} \mathrm{C}$

(b) Di-butyl-1- ${ }^{14} \mathrm{C}$-tin-bis(monomethyl)-maleate

Figure 6(a)

Figure 6(b)

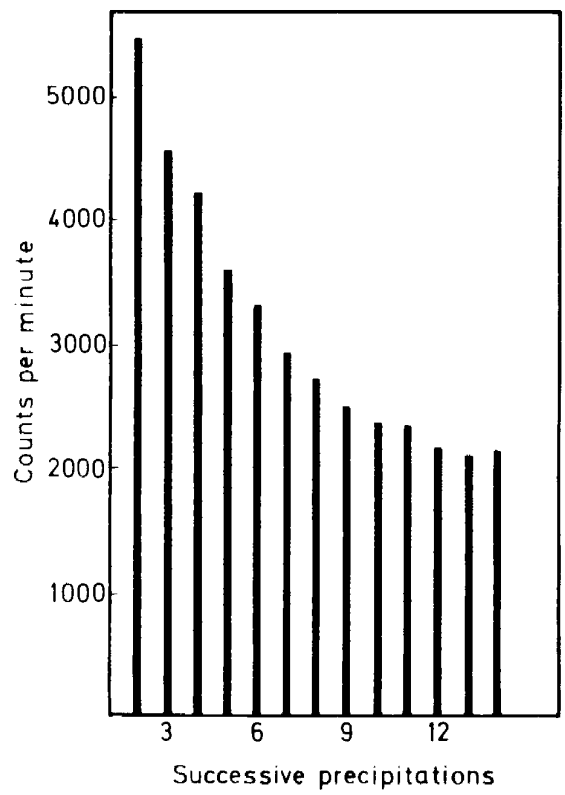

Figure 6(c). PVC with dibutyl- ${ }^{113}$ tin-bis-(monomethyl)-maleate after heat treatment

Figure 6. Retention of radioactivity by PVC after heat treatment: (a) $\mathrm{Cd} 2$-ethylhexanoate-1 $-{ }^{14} \mathrm{C}$;

(b) di-butyl-1-14 C-tin-bis-(monomethyl)-maleate 
all this work, the polymer-stabilizer compounds are separated from the low molecular products by precipitation processes and almost purified by repeated 're-precipitation'. Whereas no structural modifications were indicated in the course of repeated precipitations for PVC-N- and also PVC $-{ }^{14} \mathrm{C}$-carboxylate compounds which were formed by reaction of $\mathrm{PVC}$ with labelled cadmium soaps under the influence of heat [Figure 6(a)], a decrease of the ${ }^{14} \mathrm{C}$ and ${ }^{113} \mathrm{Sn}$ contents in relation to the number of reprecipitations of the appropriately labelled PVC-dibutyl-tin-bis-monomethyl-maleate compounds formed after heat treatment was to be noticed [Figures 6(b) and (c)], which approaches a stable final value after ten to twelve re-precipitations. The degree of the decrease of radioactivity and thus of the chemical changes of the polymer-stabilizer compound both depend on the solvent-precipitant couple and the quantities used (Figure 7)

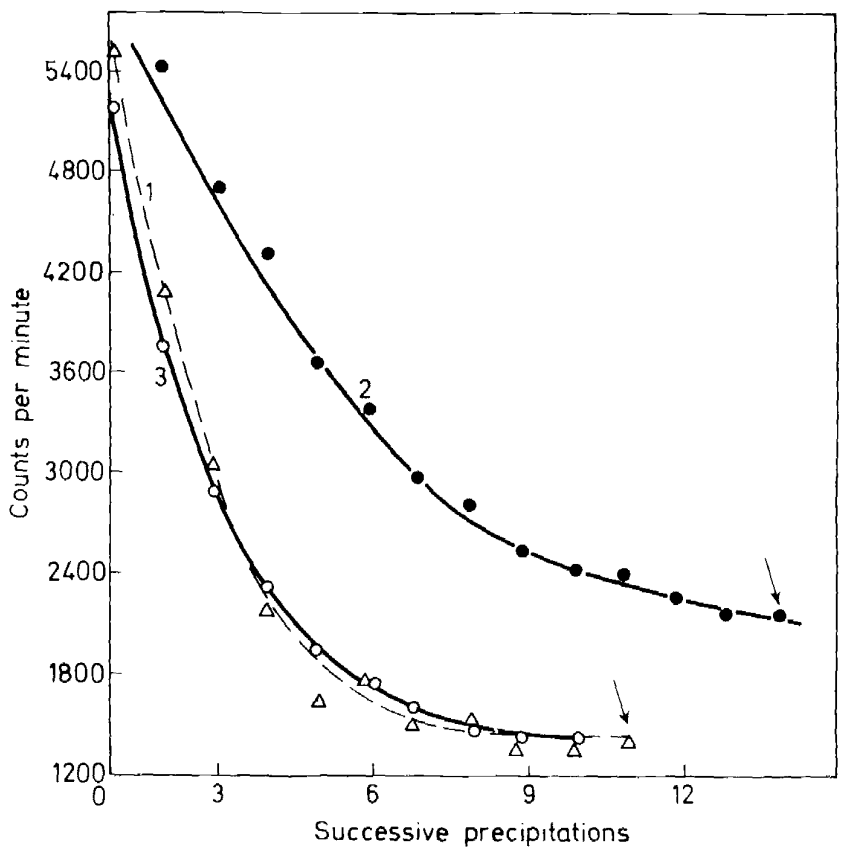

Figure 7. Influence of solvents on radioactivity on precipitation: (1) $3 \% \mathrm{PVC}$ in THF; (2) $7.5 \%$ $\mathrm{PVC}$ in THF : (3) $7.5 \%$ PVC in cyclohexanone

which are of decisive importance for stabilizer analysis, since it will be necessary in future to refrain from the rule of thumb of a solvent-precipitant relationship of $1: 10$ and to carry out special scientific preliminary tests. As may be seen from Figure 7, the rearrangement rate of the polymerstabilizer compound with precipitation in about three per cent solutions in THF with 2.5 times the quantity of methanol is higher (curve 1) as compared 


\section{ELISABETH SCHROEDER}

to a $7.5 \%$ PVC-THF solution (curve 2). When using cyclohexanone (curve 3 ), the same results as with the more diluted PVC-THF solution were obtained. Frye et al. ${ }^{17}$ concluded from the dependence on the tetrahydrofuran content on the one hand and the lability towards anhydrous hydrogen chloride on the other that a complex may exist between the corresponding tin compound and the polymer backbone molecule which is destroyed by tetrahydrofuran, cyclohexanone, methanol and mainly by hydrogen chloride as is to be seen from the illustration in Figure 8.
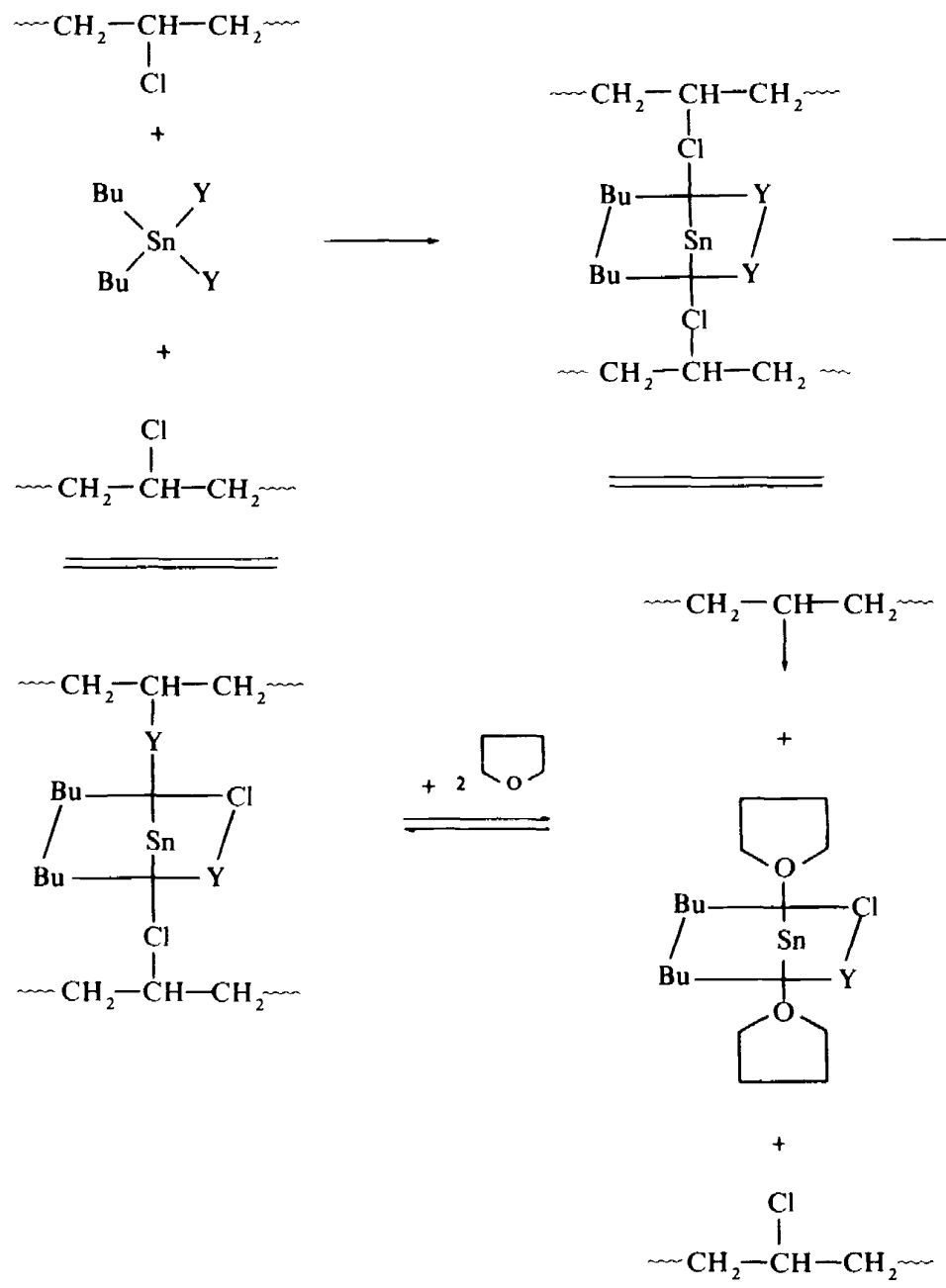

Figure 8 


\section{EXAMINATION METHODS FOR STABILIZERS}

The rearrangement of the complex by the exchange of unstable chlorine atoms with the organic residue and its insertion after splitting of the complex is indicated by the remaining constant residual activities. The need for future definitive studies with regard to the interactions between solutionprecipitant systems and polymer-stabilizer compounds may be deduced from the detail of this representation.

\subsubsection{Separation of stabilizer systems}

2.1.2.1. Thin-layer chromatography (TLC)-From all the known analytical separation processes, the greatest success so far for the problems of the stabilizer analysis has been obtained by thin-layer chromatography. Good separation efficiency in connection with high separation speed and great variability of the detection possibilities are the most important causes for this choice of treatment. Optimum working conditions for thin-layer chromatographic separation and identification have been published for all known stabilizer groups (see Table 3). Apart from the variation of carrier

Table 3. Thin-layer chromatographic methods for separation of stabilizers ${ }^{1}$

\begin{tabular}{|c|c|c|c|}
\hline Substances separated & Stationary phase & Mobile phase & Detection \\
\hline Organo-tin stabilizers & Silica-gel G & $\begin{array}{l}n \text {-Butanol-acetic } \\
\text { acid, } 98: 2\end{array}$ & $\begin{array}{l}\text { u.v. }+\mathrm{Br}_{2} \text {-dithizone } \\
\text { in chloroform }\end{array}$ \\
\hline Organic stabilizers & Silica-gel G & $\begin{array}{l}\text { Ethanol-free } \\
\text { chloroform }\end{array}$ & \\
\hline Antioxidants & Silica-gel G & $\begin{array}{l}\text { 1. Benzene } \\
\text { 2. Light-petroleum- } \\
\text { benzene- } \\
\text { acetic acid = } \\
1: 1: 1 \\
\text { 3. Cyclohexane- } \\
\text { diethylamine } 4: 1 \\
\text { and others }\end{array}$ & $\begin{array}{l}0.05 \% \mathrm{Fe}_{2}\left(\mathrm{SO}_{4}\right)_{3} \text { in } \\
\text { sulphuric acid }+0.2 \% \\
\mathrm{~K}_{4} \mathrm{Fe}(\mathrm{CN})_{6} 1: 1 \\
0.1 \% 2,6-\text { Dichloro- } \\
\text {-benzoquinone-4- } \\
\text { chloramine in } \\
\text { Ethanol }\end{array}$ \\
\hline Salicylates & Alumina + polyester & $m$-Xylene & Diazotized \\
\hline Resorcinol-derivatives & $+\mathrm{H}_{2} \mathrm{O}+\mathrm{C}_{2} \mathrm{H}_{5} \mathrm{OH}$ & Formic acid & $\begin{array}{l}\text { 1-Amino- } \\
\text { anthraquinone }\end{array}$ \\
\hline \multirow[t]{2}{*}{ Benzophenones } & $+\begin{array}{l}\text { Sodiumdiethyl- } \\
\text { di-thiocarbaminate }\end{array}$ & $98: 2$ & \\
\hline & Silica-gel G & $\begin{array}{l}\text { Chloroform- } \\
n \text {-Hexane 2:1 }\end{array}$ & $\begin{array}{l}\text { Diazotized } \\
\text { sulphanilic- } \\
\text { acid or other } \\
\text { diazotized agents }\end{array}$ \\
\hline Benzotriazoles & Silica-gel G & $\begin{array}{l}\text { Benzene } \\
\text { Benzene-light } \\
\text { petroleum } 7: 3\end{array}$ & u.v.-light \\
\hline
\end{tabular}

material, mobile phase and spray reagents, multi-stage processes here also offer prospective possibilities for the separation of complex stabilizer systems. The thin-layer chromatographic separation process for antioxidants by van der Neut ${ }^{22}$ should be mentioned here as an excellent example, where the antioxidants are first decomposed on silica gel by benzene in six groups of 


\section{ELISABETH SCHROEDER}

increasing $R_{\mathrm{F}}$ values, and afterwards are separated selectively with another nine eluant systems and identified by variation of four detection substances $^{1.2}$.

Despite all efforts for improvement of the reproducibility of the $R_{\mathrm{F}}$ values no thorough changes are to be noticed for the quantitative stabilizer analysis, although favourable conditions are provided by the possible combination with physical measuring methods of high sensitivity such as fluorimetry (x-ray and u.v.). Apart from thin-layer chromatographic interfering effects in the main the high purity requirements regarding not only all chemicals and apparatus but also the stabilizers to be investigated are of detrimental influence since impurities may result in uncontrollable quenching effects.

2.1.2.2. Gas chromatography $(G C)$-As may be deduced from values of the inherent volatility of the stabilizers already given-in particular those of the antioxidants -some stabilizers may be separated directly by gas chromatography with maximum efficiency. In the majority of the cases known these conditions, however, are not given so that separation by gas chromatography is only possible after the stabilizers have been transferred into easily volatile compounds. This method is not very important because of the material losses often encountered with it, although the separation efficiency of $\mathrm{GC}$ has not yet been reached by any other chromatographic process.

2.1.2.3. Liquid chromatography ( $L C$ )-Due to theoretical investigation into the problem, liquid chromatography could approach the dissolving power of GC. Liquid chromatography has sustained tremendous development over the past ten years and is today the most universal chromatographic principle. It is a well-known fact that the dissolving power in chromatography in general depends on three factors: the number of theoretical plates $N$, the relative selectivity $\Delta K / K$ and the relationship between the migration rate of the corresponding zone and that of the liquid phase $(R)$

$$
R_{\mathrm{s}}=(N / 16)^{\frac{1}{2}}(\Delta K / K)(1-R)
$$

( $K$ is here a thermodynamic member and corresponds to the median distribution coefficient of two neighbouring coefficients.) Under the assumption of almost equal selectivities in the gas and liquid phases and a uniform $R$ value of 0.5 with GC and LC which is common in practice, an approach of LC to the efficiency of GC is given as far as comparable $N$ values or heights of equivalent theoretical plates (HETP) which are closely related to this are obtained. They may be almost realized by newly developed carrier materials.

The new high-efficiency carrier materials are mainly particles with a solid core and a thin porous envelope with particle diameters in the micro range. Majors ${ }^{23}$ has tested the commercial carrier materials in an automatic high-pressure liquid chromatograph system with antioxidants. He has separated a four-component mixture of aromatic amines at HETP values of $\ll 1 \mathrm{~mm}$ with good reproducibility on Corasil I (glass bed with single layer of porous silica gel) loaded with $\beta, \beta^{\prime}$-oxydipropionitrile within ten minutes (Figure 9). He also achieved separations of phenolic antioxidants as well as quantitative determinations in extracts of polyacetals the results of which are much superior to those of the i.r.-spectrometric determination due to the 
high resolution with liquid - solid column chromatography (LSCC). Further applications of this more recent variant of LC in stabilizer analysis give ground for optimism.

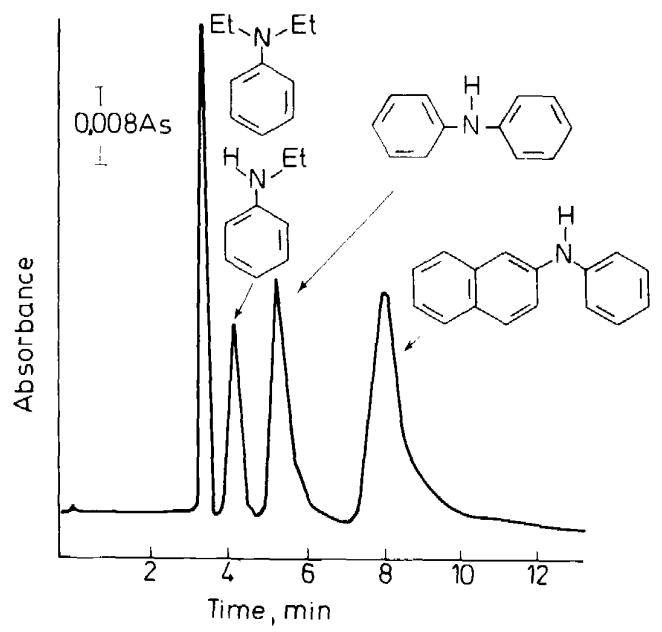

Figure 9. Separation of aromatic amine antioxidants using corasil 1

\section{PROBLEMS OF STRUCTURE EXAMINATION}

\subsection{Stable decomposition products}

Structure examinations of the stable decomposition and destruction products of stabilizers in principle correspond to classical organo-analytical concepts after separation from the polymers and exact preliminary separation. Therefore the methodological developments should not be described here in detail but progress made will be indicated by means of the present standard of knowledge. Up to now, analysis of the decomposition and transformation products has been done predominantly under the aspects of using stabilizer-containing polymers as packing materials for foodstuffs and semi-luxury goods as commodity, i.e. from the health point of view, and therefore it is essentially teamwork involving numerous disciplines with in part highly differentiated methodological solution possibilities. The most important of the decomposition products of the stabilizers were those of the tin compounds since they must be determinable even in the micro range because of some high toxicities.

Franzen et al. ${ }^{25}$ were able to confirm the formation of tri- and monooctyl-tin compounds, which may be formed by disproportionation, in pure di-n-octyl-tin-maleate after eight hours thermal load at $180^{\circ} \mathrm{C}$ by means of thin-layer chromatographic examinations which reveal with certainty alkyl-tin compounds in concentrations as low as $2 \gamma$ tin:

$$
2 \mathrm{R}_{2} \mathrm{SnY}_{2} \rightarrow \mathrm{R}_{3} \mathrm{SnY}+\mathrm{RSnY}_{3}
$$


The extent of disproportionation depends on the acid residue $Y$ and is caused by strong Lewis acids as occur in the form of hydrogen chloride during thermal decomposition of PVC. Consequently, it was possible to identify these compounds even in heat-treated PVC films after aggravated extraction conditions (heptane-glacial acetic acid). From the negative result of the experiment after normal extraction (ether) it was an obvious conclusion

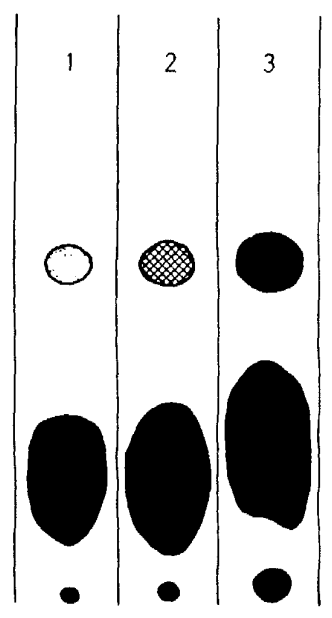

Figure 10. Detection of tri- $n$-octyl-tin in PVC after heat treatment : (1) di-n-octyl-tin-maleate; (2) extract before heat treatment ; (3) extract after heat treatment

that here again a coordinative bonding similar to the PVC-organotin complexes already mentioned prevails (Figure 10). Therefore damage to health through the highly toxic tri-alkyltin compounds in heat-loaded PVC need not be expected because they are present only in small quantities (less than five per cent of the stabilizer used).

In addition, pure decomposition products were identified with stabilizers based on urea ${ }^{20,27}$. Phenylisothiocyanate, diphenylurea, aniline and triphenylguanidine could be identified with certainty again by TLC when heating diphenylthiourea $\left(15\right.$ minutes to $\left.165^{\circ} \mathrm{C}\right)$ with $0.1 \mathrm{~N}$ hydrochloric acid. The same decomposition products are also to be found in processed PVC films as well as nitrogen-containing PVC reaction products. The decomposition reactions resulting in these products are shown in Figure 11.

They can be detected not only in the i.r. but also in the u.v. spectrogram. Here the intensity maximum proper at $35500 \mathrm{~cm}^{-1}$ is much overlapped by decomposition products (Figure 12) and this forbids any direct determination in the films by u.v. spectrometry. This fact should hold true for numerous other systems as well so that direct determination may not always be fruitful.

The same decomposition products were found with the sulphur-free urea derivatives. In the course of PVC processing 2-phenyl-indole also suffers from decompositions which can be detected by the sudden extinguishing of luminescence. This extremely sensitive detection method is of general 

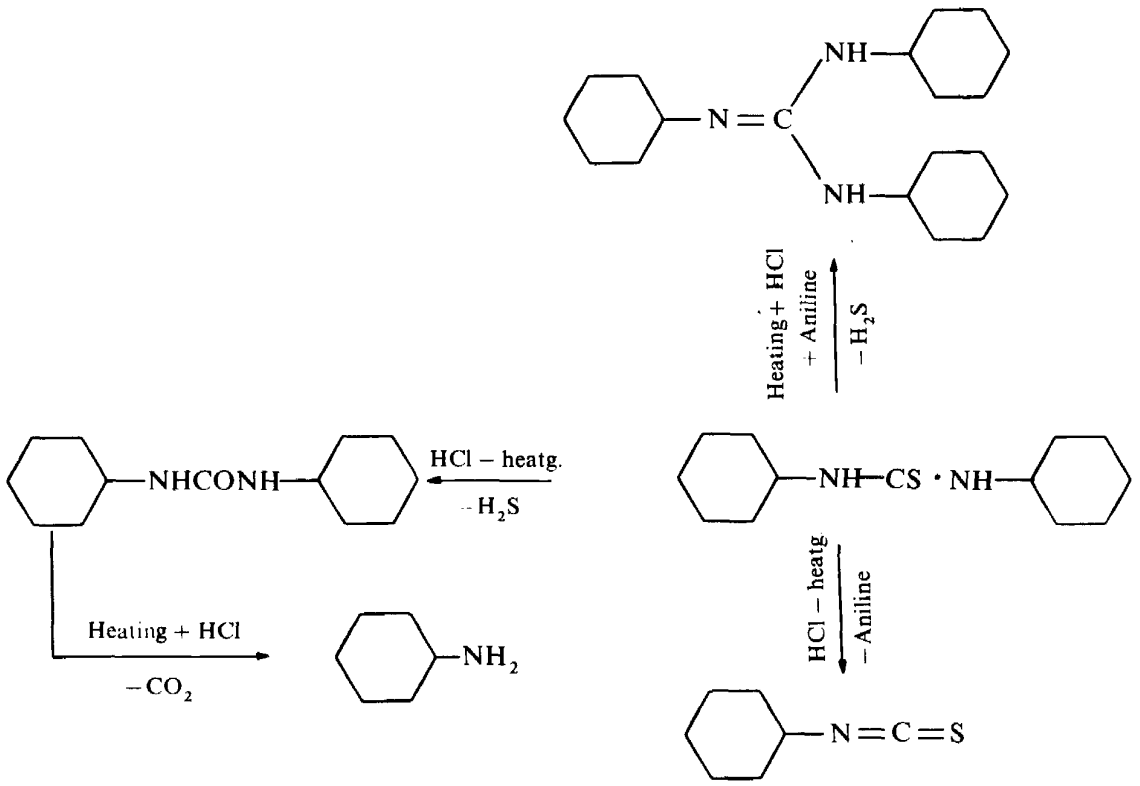

Figure 11. Destruction reactions of diphenylthiourea with hydrochloric acid after heating

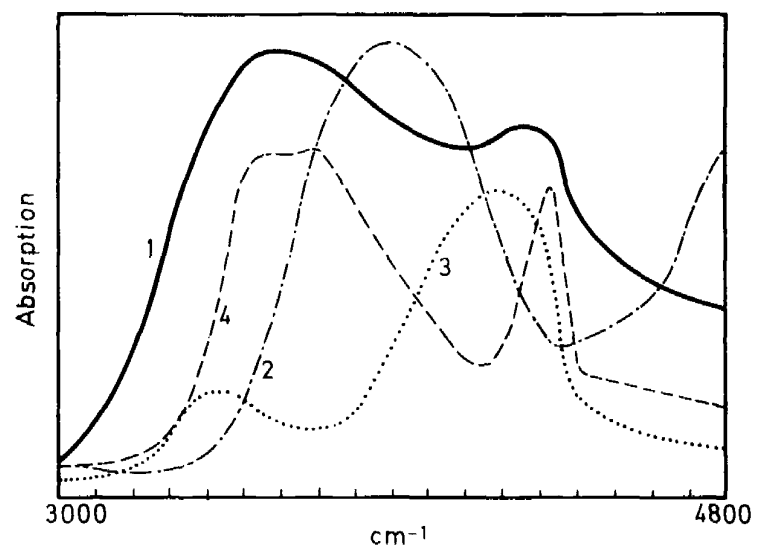

Figure 12. The u.v. spectrum of: (1) diphenylthiourea; (2) diphenylurea; (3) aniline; (4) phenylisothiocyanate 
importance for stabilizer analysis, in particular for following the time sequence of the reactions, because the stabilizers are often u.v. absorbers which change into an excited condition under the influence of light emitting electrons, and are deactivated under emission of light ${ }^{26}$. If the spectral decomposition of the emission light follows the intensity measurement, the luminometry is suitable for structure investigations of the stabilizers and their conversion products, although the spectra such as the absorption spectra in the u.v. are highly superposed and not very selective. It was possible amongst others to identify from the luminescence spectra of di- $\beta$-naphthyl- $N$-phenylenediamine, di- and triphenylamine after the influence of light.

\subsection{Stable transformation products}

The examination of nitrogen-containing antioxidants from among the stable transformation products has been given preference because of their certain analytical determination. From kinetic examinations which were supported by isotope analysis, e.p.r. measurements and quantitativemainly u.v. or i.r.-spectrometric determination of inhibitor consumption, the reactions I-III are discussed out of the known mechanisms of oxidation inhibition of hydrocarbons (see Figure 13)-independently of the molecular

$$
\begin{aligned}
& \mathrm{RO}_{2}+\mathrm{AH} \longrightarrow \mathrm{ROOH}+\mathrm{A} \cdot \\
& \mathrm{RO}_{2} \cdot+\mathrm{NH}_{\mathrm{RO}}:^{-}+\mathrm{NH}^{+} \\
& \mathrm{RO}_{2} \cdot \mathrm{AH}=\left(\mathrm{RO}_{2} \cdot \longrightarrow \mathrm{AH}\right) \\
& \left(\mathrm{RO}_{2} \cdot \mathrm{AH}\right)+\mathrm{RO}_{2} \longrightarrow \text { stable products } \\
& \mathrm{RO}_{2} \cdot \mathrm{AH} \longrightarrow \mathrm{RO}_{2}-\mathrm{AH} \cdot
\end{aligned}
$$

Figure 13. Reaction of antioxidants

size of the hydrocarbon. Amongst these reactions, that of hydrogen transfer for primary and secondary amines is perhaps the most probable one. Therefore amine radicals, radical ions, peroxy radical-inhibitor complexes as well as stable products are possible intermediary products. The deactivation process occurs mainly by way of dimerization, disproportionation or $\mathbf{H}$ transfer from the inhibitor radical. Quinone imides or diimides are final products of the last-mentioned reaction which were identified with certainty in the oxidation of $N, N^{\prime}$-diphenyl-p-phenylene-diamine (Figure 14,1$)$ through their u.v. spectra.

With i.r. analysis of the extracts of oxidation products of rubber in the presence of $N$-phenyl-2-naphthylamine, the existence of dimer final products is deduced on account of the decrease of the NH band as well as the increase of the $\mathrm{C}-\mathrm{N}$ and $\mathrm{N}-\mathrm{N}$ bands. 
These final products are formed by radical recombination ${ }^{28}$ (Figure 14,2 ). In addition to this, other reactions of the intermediary products with rubber can take place. These reactions were examined thoroughly by analyses with rubber vulcanizates by Tsurugi et $a l^{21}$. It was possible by means of acetone extraction of the oxidized vulcanizates which contained secondary mono- and diamines as well as tertiary amines as antioxidants, to isolate the amines not converted and the quinone diimines and to determine them quantitatively by a combination of potentiometric titration, GC and u.v. spectrometry. Semiquinone cations were found by treating the extraction residue with hydrochloric acid-ethanol and subsequent u.v. analysis. These semiquinone cations may only result from the hydrochloric acid splitting of the $\pi$-complex between a rubber-peroxy radical and the inhibitor formed according to reaction 3 (Figure 14). The extraction residue of the hydrochloric acid extraction also contained stable rubber-inhibitor reaction

1.<smiles>c1ccc(Nc2ccccc2)cc1</smiles>

Detection Lit.

$+2 \mathrm{RO}_{2}^{*}$

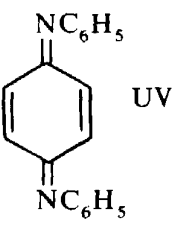

2.<smiles>c1ccc(Nc2ccc3ccccc3c2)cc1</smiles>

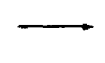<smiles>[R17]c1ccccc1N(c1ccc2ccccc2c1)N(c1ccccc1)c1ccc2ccccc2c1</smiles><smiles>[R]O[R6](=O)[OH+]Nc1ccc(Nc2ccc(Nc3ccccc3)cc2)cc1</smiles>
3.<smiles>O[R20](Cl)[I-]</smiles>

Figure 14. Stable reaction products of amine antioxidants

products. This successful combination of selective separation and analytical determination processes (Figure 15) permitted the direct identification, for the given example, of the reaction mechanism of inhibition during rubber oxidation through the intervention of the charge-transfer complex. 


\section{ELISABETH SCHROEDER}

Depending on the resonance stabilization of the radicals which may be detected and interpreted in their structure, both benzenoid and quinonoid products are to be found with the phenolic antioxidants. The first stable conversion products of 4-methyl-phenoles found from systematic examinations with $\mathrm{PP}^{8}$ were polymer quinones which change into low molecular quinones in the course of further oxidation.

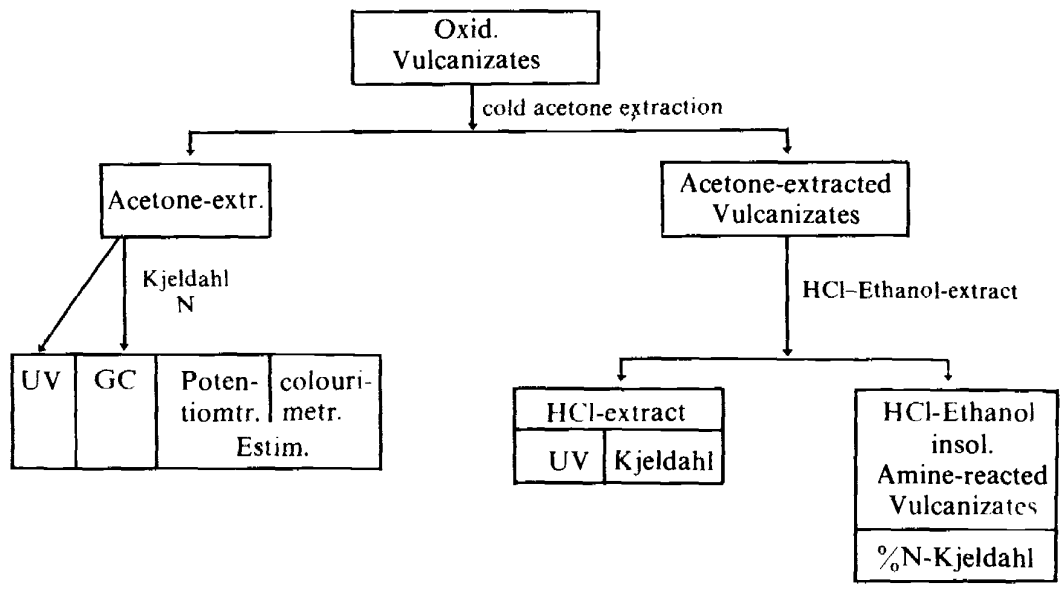

Figure 15. Analytical procedure for oxidized vulcanizates

As can be seen from the last analysis diagram, the explanation of the structure of stable intermediate and final products of the reactions between polymers and stabilizers is only possible by combining largely selective separation processes with all analytical detection and determination processes of high sensitivity and selectivity adapted to the system. We are still at the beginning in the explanation of the structures of polymer-stabilizer reaction products. Up to now, radiochemistry has brought about the biggest progress here.

\section{REFERENCES}

' E. Schröder. E. Hagen and J. Franz, Ausgewählte Methoden zur Plastanalytik, AkademieVerlag: Berlin (in preparation).

2 D. A. Wheeler, Talanta, 15/12, 1315 (1968).

${ }^{3}$ E. Schröder, E. Hagen and M. Helmstedt, Plaste Kautsch. 14, 560 (1967).

4 T. Pazonyi, M. Tüdös and M. Dimitrov, Angew. Makromol. Chem. 10, 75 (1970).

5 A. S. Kenyon, Nat. Bur. Stand. Circ. No. 525, 81, 87, 100 and 106 (1953).

${ }^{\circ}$ A. H. Frye, R. W. Horst and A. Mako, J. Polym. Sci. A2, 1765(1964).

7 S. S. Yushkevichyute and Yu. A. Shlyapnikow, Plast. Massy, 12, 62 (1966).

${ }^{8}$ L. L. Yasina, B. A. Gromov, V. B. Miller and Yu. A. Shlyapnikow, Vysokomol. Soedin. 8, 1411 (1966).

"E. Schröder, and G. Rudolph, Plaste Kautsch. 10, 22 (1963).

10 J. Coupek, S. Pokorný and J. Pospišil, Lecture XI. Microsymposium on Macromolecules, Prague (1972). 


\section{EXAMINATION METHODS FOR STABILIZERS}

11 J. Protivová, J. Pospísil and L. Zikmund, Lecture XI. Microsymposium on Macromolecules, Prague (1972).

12 D. F. Alliet and J. M. Pacco, Separation Sci. 6, 153 (1971).

13 R. D. Mate and H. S. Lundstrom, J. Polym. Sci., Part C, 21, 317 (1968).

14 F. N. Larsen, Amer. Lab. 10, 10 (1969).

15 A. H. Frye and R. W. Horst, J. Polym. Sci. 40, 419 (1959).

16 A. H. Frye and R. W. Horst, J. Polym. Sci. 45, 1 (1960).

17 A. H. Frye, R. W. Horst and M. A. Paliobagis, J. Polym. Sci. A, 1785 (1964)

18 A. H. Frye, R. W. Horst and M. A. Paliobagis, J. Polym. Sci. A2, 1801 (1964).

19 R. Schlimper, Plaste Kautsch. 10, 19 (1963).

${ }^{20}$ E. Schröder, E. Hagen and S. Frimel, Plaste Kautsch. 14, 158, 814 (1967).

21 J. Tsurugi, S. Murakami and K. Goda, Rubber Chem. Technol. 44, 857 (1971).

22 J. H. van der Neut and A. C. Maagdenburg, Plastics, London, 31, 66 (1966).

23 R. E. Majors, J. Chromatogr. Sci. 8, 338 (1970).

${ }^{24}$ K. Thinius, Stabilisierung und Alterung von Plastwerkstoffen, Akademie-Verlag: Berlin (1969).

25 V. Franzen and G. Neubert, Chemiker Ztg. 23, 801 (1965).

${ }^{26}$ R. N. Nurmukhametov, L. V. Bondareva, D. N. Shigorin, N. V. Mikhailov and L. G. Tokareva. Hochm. Verb. UdSSR, 6, 1411 (1964).

27 C. E. Boozer, G. S. Hammond, C. E. Hamilton and N. S. lyotirindra. J. Amer. Chem. Soc. 77, 3233 (1955).

28 J. G. Angert and A. S. Kuzminski. J. Polym. Sci. 32, 1 (1958). 